\title{
On the Somatic Chromosomes in Lathyrus
}

\author{
By \\ Basudev Roy. M. Sc., \\ Department of Botany, Calcutta University
}

Received November 25, 1935

Much attention has been drawn in recent years to the study of the morphology of chromosomes of both plants and animals and results of great importance have been obtained elucidating many critical problems in genetics and heredity. As regards the structure and division of chromosomes, there are different schools of cytologists holding different views. The difference of opinion in some fundamental points is so great that it induces every student of biology towards further research on chromosome structure.

The present work was undertaken with a view to study the structure and division of the somatic chromosomes in Lathyrus sativus Linn.

\section{Material and method}

Root tips of germinating seeds of Lathyrus were fixed in Allen's modification of Bouin's fluid, Navashin's fluid, and in Flemming's weak solution. The fixation was carried on between 10 A.M. and 9 P.M. The material fixed between 1 P.M. and 3 P.M. showed numerous dividing nuclei. The fixed material was washed and dehydrated in the usual way and cleared in cedar oil and imbedded in paraffin of $56-58^{\circ} \mathrm{C}$. M. P.

Sections were cut $3 \mu$ to $10 \mu$ thick and stained in iron alum haematoxylin both by short and long methods and in Newton's iodine gentian violet. Staining with the former reagent did not give desirable results. Newton's iodine gentian violet gave much better results and this stain was extensively used for the present study.

\section{Observations}

An aphase. Anaphase begins with the movement of chromosomes towards the opposite poles of the spindle. During the whole anaphase stage a chromosome is seen to consist of two filiform threads of greater chromaticity lying in a less chromatic matrix (Fig. 1). On examination of the successive crossing points, the chromonemata revealed their intertwining nature. On reaching the poles the chromosomes clump together and show a very great affinity for the stains so that their individuality and internal structure are lost to sight (Fig. 2). In Lathyrus, the clumping of the chromosomes seems to be a natural phenomenon and not a case of artifact. The chromo- 
somes clump and again emerge out of this clumping gradually (Fig. 3). Such a sequence cannot be expected in a case of artifact.

Telophase. Telophase begins with the relaxing of chromosomes from polar clumping; in early telophase the karyolymph showis much affinity for the stains thus rendering our study of the chromosomes very difficult. At first only the outlines of the chromosomes are discernible. Gradually the karyolymph loses its affinity for the stains and the individuality and structure of the chromosomes become pronounced. Intertwined chromonemata become visible in a chromosome and delicate attenuations connecting adjacent chromosomes (Fig. 4).

In this investigation, Grégoire's theory of the alveolisation of the telophase chromosomes cannot be corroborated for telophase chromosomes are seen to consist throughout of two intertwined chromonemata having the semblance of vacuolated chromosomes. Most probably Grégoire's failure to detect the chromonemic structure of a chromosome led to such assumption.

With the progress of telophase, the nuclear membrane makes its appearance and soon after its formation, one or more nucleoli appear (Figs. 5 \& 6).

In the telophase, anastomoses are seen in abundance connecting the chromosomes which have by this time become very thinner and consequently longer (Fig. 7). In still later telophase, the chromosomes become uninteligible in character. This may be attributed to the extensive development of the anastomoses and to the thining of the chromosomes. The less chromatic matrix in a chromosome has disappeared by this time; of course in this investigation the proof of its presence or absence is confined to its staining property only.

Resting stage. The resting nucleus contains a net work of fine threads. Duality of these threads is not at all discernible. Drawing sequence from the late telophase this much can be said without error that these threads represent the chromosomes and their anastomoses. In fact the chromosomes have become so thin that it is not at all discernible which portion of the threads belong to the chromosomes and which portion, to their anastomoses (Fig. 8).

Prophase. Nuclei entering prophase show the following changes-1. the gradual withdrawal of the anastomoses, 2 . the thickening of the chromosome threads and 3. an increase in affinity of the threads for the stains. The withdrawal of the anastomoses and thickening of the chromosome threads are long processes and innumerable intermediate stages are seen between the onset and completion of these processes. The individuality of the chromosomes becomes gradually recognizable and when the chromosomes have attained a moderate thickness, their duality (the chromonemata and 

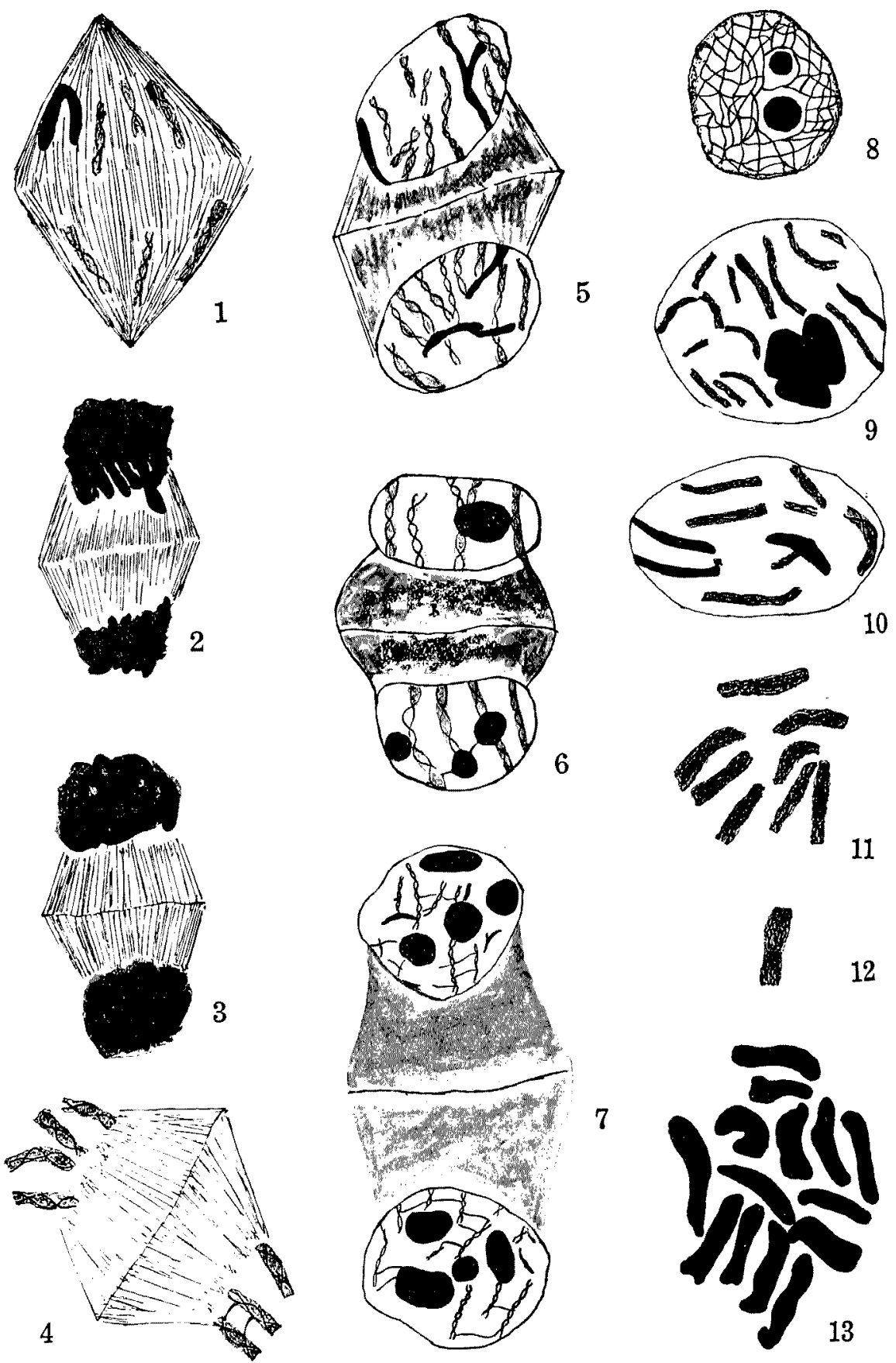

Figs. 1-13. All figures were drawn with the belp of a Zeiss camera-lucida at table level, with Leitz I/12 inch oil imm., N. A. 1.32 and Zeiss ocular No. 15 and immersed aplanatic condenser N.A. 1.2. Magnification of all figures is $\times 2800$. Fig. 1. Anaphase: chromosomes showing duality of the chromatic elements. Flemming. Iodine 
the less chromatic matrix) becomes visible (Figs. $9 \& 10$ ). As prophase progresses, the nucleolus decreases in size, the corroding process being very varied; sometimes it takes place more or less uniformly over the whole surface of the nucleolus and sometimes it is much greater at some points, the result being that the nucleolus sometimes assumes a two-, three- or many-lobed appearance (Fig. 9) ; in all cases however the nucleolus disappears in the late prophase. It is interesting to note here that two processes go on simultaneously namely the corroding of the nucleolus and the increase in chromaticity of the chromosomes. It is more interesting to note that by late prophase when the chromosomes have attained sufficient chromaticity and are nearly ready for division that the nucleolus disappears to reappear only in relatively late telophase when the chromosomes seem to lose much of their chromaticity. Summing up these evidences, one is led to assume that the nucleolus plays an active role in chromosome division.

It is very important to record that some of the prophase chromosomes showed beaded appearance of their chromonemata, though these beads were few in number.

The less chromatic matrix of the chromosome is persistent throughout the whole prophase from the time the duality of the chromosome becomes visible. The nuclear membrane finally disappears and the spindle gradually makes its appearance.

Metaphase. The chromosomes are at first scattered over the spindle, but gradually they become arranged at the equatorial plate. In spite of their great affinity for the stains, the duality of the chromosomes is very clear and in well differentiated sections each chromonema in every chromosome showed distinctly beaded appearance and

gentian violet. Fig. 2. Beginning of polar clumping: internal structure of the chromosomes is obscured. Flemming. Iodine gentian violet. Fig. 3. Polar clumping : later than above, individuality of the chromosomes is not clearly discernible, but it is not completely obscured. Flemming. Iodine gentian violet. Fig. 4. Early telophase. Chromosomes showing intertwined chromonemata. Flemming. Iodine gentian violet. Fig. 5. Telophase. Later than above; chromosomes showing increased twining of the chromonemata. Nuclear membrane has appeared. Flemming. Iodine gentian violet. Fig. 6. Telophase. Nucleoli have appeared. Flemming. Iodine gentian violet. Fig. 7. Telophase. Chromosomes have become much thinned; intertwining aspect of the chromonemata is very remarkable. Anastomoses are abondant. Flemming. Iodine gentian violet. Fig. 8. Resting nucleus showing reticular structure of the chromatic threads. Flemming. Iodine gentian violet. Fig. 9. Prophase. Chromosomes showing internal structure. Corroding of the nicleolus is to be noted. Flemming. Iodine gentian violet. Fig. 10. Prophase. Later than above, nucleolus bas disappeared. Flemming. Iodine gentian violet. Fig. 11. Metaphase plate chromosomes showing beaded character of chromonemata. Flemming. Iodine gentian violet. Fig. 12. Metaphase chromosome showing the organisation of the daughter chromosomes. Flemming. Iodine gentian violet. Fig. 13. Metaphase plate: chromosomes show their heteromorphic nature. Flemming. Iron alum haematoxylin. 
these beads were quite large in number (Fig. 11). The metaphase plate stage is of fairly long duration and at this stage the chromo. nemata were much untwined. The next stage that was found was the duality of each chromonema in a chromosome or the quadruple structure of a chromosome (Fig. 12).

In the metaphase plate stage, the chromosomes were examined from sections of varying thickness. It was found that the somatic chromosomes in Lathyrus are 14 in number and that they are heteromorphic (Fig. 13).

\section{Discussion}

The chromosome in Lathyrus is made up of two chromonemata imbedded in a less chromatic matrix which begins to disappear during the telophase stage leaving no sign of it in the late telophase, the chromonemata maintaining the genetic continuity of the chromosomes through the resting stage; whether the less chromatic matrix disappears in the nucleoplasm or disappears to be stored up in the nucleolus is very difficult to be said with certainty. From the early prophase again the less chromatic matrix is recognisable and persists through metaphase and anaphase, up to the early telophase. Paired chromonemata in a chromosome is visible in almost all stages being obscured in the late telophase and resting stages only. This obscurity is again due to the extensive development of the anastomoses and thinness of the chromosome threads. Lastly the quadruple structure of the metaphase chromosome leaves no doubt about the fact that the duality of the chromonemata is a normal and constant feature of a Lathyrus chromosome. So about the duality of a chromosome the author corroborates the findings of Kaufmann (1926), Sharp (1929), Telezynsky (1930, 1931), Hedayetullah (1931) and Koshy (1933).

The supporters of the dual chromonema in a chromosome are of different opinion about the time of chromosome division. Kaufmann (1926) and Sharp (1929) observed the chromosomes to divide in prophase while Hedayetullah (1931) and Koshy (1933) maintain that the chromosome divides in the metaphase plate stage. In the present work, the writer observed the first evidence of the division of the chromosome in its quadruple nature which was absent from the prophase chromosomes. Hence the Lathyrus chromosome seems to divide at the metaphase plate stage.

\section{Summary}

1. The anaphase chromosome is composed of two intertwined chromonemata (chromatic threads) lying in a less chromatic matrix.

2 . The duality of the chromosome is temporarily obscured during the "tassement polaire" or polar clumping stage. 
3. At telophase, the less chromatic matrix of the chromosome gradually disappears and the chromonemata maintain the genetic continuity of the chromosome.

4. Individuality of the chromosomes and of the chromonemata are not recognisable in the late telophase and the resting stage of the nucleus.

5. Individuality of the chromosomes and of the chromonemata become again visible in the comparatively advanced prophase stage.

6. The less chromatic matrix reappears in the early prophase.

7. At the equatorial plate stage, each of the two chromonemata of a chromosome gives rise to two daughter chromonemata thus giving rise to a quadruple structure of the mother chromosome.

In conclusion I wish to express my gratitude to Prof. S. P. Agharkar for facilities offered during the progress of this investigation.

\section{References}

Bolles-Lee, A. (1920). The Structure of Certain Chromosomes and the Mechanism of their Division. Quart. Jour. Micr. Sci. 65, 1-32.

(1924). The Chromosomes of Paris quadrifolia and the Mechanism of their Division. Ibid. 69, 1-25.

Bonnevie, Kristine (1908). Chromosomenstudien. I. Arch. Zellf. 1, 450-514.

- (1911). Chromosomenstudien. III. Chromatinreifung in Allium cepa. Ibid. 6, 190-253.

Digby, L. (1910). The Somatic, Premeiotic, and Meiotic Nuclear Division of Galtonia candicans. Ann. Bot. 24, 727-57.

(1919). On the Archesporial and Meiotic Mitoses in Osmunda. Ann. Bot. 33, 160-172.

Earl, R. O. (1927). The Nature of Chromosomes. I. Effects of Reagents on Root Tip Sections of Vicia faba. Bot. Gaz. 84, 68-74.

Fraser, H. C. I. (1914). The Behaviour of the Chromatin in the Meiotic Divisions of Vicia faba. Ann. Bot. 28, 633-42.

- and Snell, J. (1911). The Vegetative Division in Vicia faba. Ann. Bot. 25, 845-55.

Gates, R. R. (1912). Somatic Mitoses in CEnothera. Ann. Bot. 26, 993-1010.

Grégoire, V. (1906). La structure de l'élément chromosomique au repos et en division dans las cellules végétales (Racines d'Allium). La Cellule 23, 311-53.

- and Wygearts, A. (1903). La reconstitution du noyau et la formation des chromosomes dans les cineses somatiques. I. La Cellule 21, $5-76$.

Hedayetullah, S. (1931). On the Structure and Division of the Somatic Chromosomes in Narcissus. Journ. R. Micr. Soc. 51, 317-386.

Kaufmann, B. P. (1926). Chromosome Structure and its Relation to the Chromosome Cycle. I. Somatic Mitosis in Tradescantia pilosa. Amer. Jour. Bot. 13, 59-80.

Koshy, T. K. (1933). Chromosomes Studies in Allium. I. The Somatic Chromosomes. Jour. R. Micr. Soc. 53, 299-318.

Kuwada, Y. (1926). On the Structure of the Anaphasic Chromosomes in the Somatic Mitosis of Vicia faba, with Special Reference to the So-called Longitudina] Split of Chromosomes in the Telophase. Mem. Coll. Sci., Kyoto Imp. Univ. B. 2, 1-13. 
Kuwada, Y. and Nakamura, T. (1933). Behaviour of Chromonemata in Mitosis. I. Observation of Pollen Mother Cells in Tradescantia refiexa. Mem. Coll. Sci., Kyoto Imp. Univ. B. 9, 129-139.

Latter, J. (1926). The Pollen Development of Lathyrus odoratus. Ann. Bot. 40, $277-313$.

Martens, P. (1922). La cycle du chromosome somatique dans les Phanérogams. I. Paris quadrifolia. La Cellule 33, 331-428.

Merriman, Mabel L. (1904). Vegetative Cell Division in Allium. Bot. Gaz. 37, 178-207.

Perry, K. M. (1932). Mitosis in Galanthus nivalis. Jour. R. Micr. Soc. 52, 344-56.

Roy, B. (1933). Studies in the Development of the Female Gametophyte in Some Leguminous Crop Plants of India. Ind. Jour. Agr. Sci. 3, 1098-1107.

Sands, H. C. (1923). The Structure of Chromosomes in Tradescantia virginica, L. Amer. Jour. Bot. 10, 343-360.

(1934). Peregenesis and the Controversy over Parasynapsis and Telosynapsis. I. Amer. Jour. Bot. 21, 402-426.

Sarbadhikari, P. C. (1924). Cytology of Osmunda and Doodia. I. On the Somatic and Meiotic Mitoses of Doodia. Ann. Bot. 38, 1-26.

Sharp, L. W. (1934). An Introduction to Cytology. 3rd Ed., New York, McGraw Hill Book Co.

(1929). Structure of Large Somatic Chromosomes. Bot. Gaz. 88, 34982.

Telezynsky, H. (1930). La cycle du chromosome somatique. I. Observations vitales sur les poils staminaux de Tradescantia virginiana, L. Acta Soc. Bot. Poloniae 7, 381-433.

(1931). La cycle du chromosome somatique chez l'Heamanthus Katharinae Back. C. R. Soc., Sci. et Lett. Versovie 23, (class IV) $115-18$.

Vejdovsky, F. (1911-12). Zum Problem der Vererbungsträger. Königl. Böhem. Gesells, d. Wiss. Prag.

(1926-27). Structure and Development of the Living Matter. Pub. Roy. Boh. Soc. Sci. Prague. 